\title{
Experimental study on the influences of fly-ash and slag on the plastic shrinkage of concrete
}

\author{
Xiaoxia $\mathrm{Wu}^{1, \mathrm{a}}$, Hongying $\mathrm{Li}^{2, \mathrm{~b}}$, Qingfu $\mathrm{Li}^{3, \mathrm{c}}$, Zhen $\mathrm{Wan}^{3^{*}, \mathrm{~d}}$ \\ ${ }^{1}$ Zhengzhou College of Traffic Technicians, Zhengzhou, 450016, China \\ ${ }^{2}$ Zhengzhou Highway Management Bureau, Zhengzhou, 450000, China \\ ${ }^{3}$ College of Water Conservancy and Environment Engineering , Zhengzhou University, Zhengzhou, \\ 450001, China \\ aemail:877950010@qq.com, bemail:937705236@qq.com, cemail: \\ Iqflch@zzu.edu.cn, ${ }^{d}$ email:wanzhenzzdx@163.com
}

Keywords: Fly-ash Slag; Concrete; Plastic; Shrinkage

\begin{abstract}
Fly-ash and slag are the commonly used concrete admixtures, and can improve the durability of concrete. In this paper, the influence rules of different contents of fly-ash and slag on the workability and the capacity of resisting plastic shrinkage of concrete were investigated through a series of experiments. The results showed that adding fly-ash and slag to concrete can improve the workability of concrete, and the area of plastic cracking was smallest with addition of $20 \%$ fly-ash and slag. The achievement of the experimental study of the article may provide some references for making anti-shrinkage concrete.
\end{abstract}

\section{Introduction}

Along with the deepening of research on concrete material, the anti-cracking performance of concrete has been an important index of the durability assessment of concrete, especially the inchoate cracks, has been drawing increasing attention. In 1942 plastic shrinkage was defined as "the volume shrinkage of cement paste (the size of shrinkage value is $1 \%$ of the absolute volume of dry cement.)" by Swayze [1], while the ACI definition of plastic shrinkage is "shrinkage occurs before the setting of cement paste, mortar or concrete". Foreign researches[2] show that this kind of cracking is mainly influenced by curing temperature, relative humidity and wind velocity of concrete, and China's Yao Mingfu and Zhan Binggen[3] found that concrete mingled with fly-ash, silica fume and other admixtures are thought to effectively improve the performance of concrete and the capacity for resisting plastic shrinkage. This paper found that with the change of contents of fly-ash and slag, the workability and the capacity for resisting plastic shrinkage in concrete change accordingly and the area of plastic cracking was smallest with the addition of $20 \%$ fly-ash and slag.

\section{Raw materials used in the experiments}

The cement is P.O42.5 ordinary portland cement that produced by Tex xinjiang cement Co., Ltd. The fineness is $3.0 \%$, the soundness remains qualified, the initial-set time and final-set time are $146 \mathrm{~min}$ and $211 \mathrm{~min}$, the $3 \mathrm{~d}$ and $28 \mathrm{~d}$ compressive strength are $23.9 \mathrm{MPa}$ and $47.6 \mathrm{MPa}$, and the $3 \mathrm{~d}$ and 28d flexural strength respectively are 4.7MPa, 8.0MPa. The fly-ash is 1 grade produced by Manasi power generation branch of Xinjiang Tianshan electric power company. The fineness is $9.22 \%$, the water demand ratio is $91 \%$, the loss on ignition is $5.24 \%$, the water content is $0.5 \%$ and the content of SO3 is $1.22 \%$. The specific surface area of slag is $4633 \mathrm{~m}^{3} / \mathrm{kg}$, the chloride ion content is $0.0242 \%$, the loss on ignition is $1.236 \%$, the water content is $0.3 \%$ and the content of SO3 is $0.29 \%$. Using natural sand as fine aggregate, the fineness modulus is 2.8 , the stacking density is $1.651 \mathrm{~g} / \mathrm{cm}^{3}$, the apparent density is $2.626 \mathrm{~g} / \mathrm{cm}^{3}$, the mud content is 0 , the robustness is $0.4 \%$, and the SO3 content is $0.009 \%$. Natural pebbles of two different particle sizes were used as coarse aggregate, the particle sizes are $5 \sim 20 \mathrm{~mm}$ and $20 \sim 40 \mathrm{~mm}$, the apparent densitys are 
$2.275 \mathrm{~g} / \mathrm{cm}^{3}$ and $2.283 \mathrm{~g} / \mathrm{cm}^{3}$, the skin drying densitys are $2.719 \mathrm{~g} / \mathrm{cm}^{3}$ and $2.671 \mathrm{~g} / \mathrm{cm}^{3}$, the crushing values are $7.3 \%$ and $7.5 \%$, and the firmnesses are all $4 \%$. Superplasticizer was used as admixture, produced by Xinjiang Hongli new material factory. The water reducing efficiency is $14 \%$, the bleeding rate is $42 \%$, and the initial-set time and final-set time are $45 \mathrm{~min}$ and $100 \mathrm{~min}$. Water is local tap water, and all the measurement results of the above raw materials comply with the related standard [4-9].

\section{Test program}

In this experiment, the apparent density hypothesis was used to produce C30 concrete, fly-ash content was $20 \%$, sand ratio was $35 \%$, the gradation of coarse aggregate was $50 \%: 50 \%$ and the water reducer content was $0.5 \%$ in the standard mixing proportion. Based on the standard mixing proportion, water consumption was kept unchanged and four kinds of water-binder ratio (0.35, $0.375,0.40,0.425)$, four kinds of content of fly ash (5\%, 10\%, 15\%, 20\%), four kinds of content of slag $(5 \%, 10 \%, 15 \%, 20 \%)$, four kinds of sand ratio (33\%, 35\%, 37\%, 39\%), four kinds of aggregate gradation (30\%:70\%, 40\%:60\%, 50\%:50\%, 60\%:40\%) were selected to design 16 sets of experiment, which are cross experiment. The variation range of influence factors is showed in table 1 and the table of orthogonal design is showed in table 2.

Table 1 . The variation range of influence factors

\begin{tabular}{|c|c|c|c|c|c|c|}
\hline A & \multicolumn{2}{|c|}{ Water-binder ratio } & 0.35 & 0.375 & 0.40 & 0.425 \\
\hline $\mathrm{B}$ & \multicolumn{2}{|c|}{ Content of fly ash } & $5 \%$ & $10 \%$ & $15 \%$ & $20 \%$ \\
\hline $\mathrm{C}$ & \multicolumn{2}{|c|}{ Content of slag } & $5 \%$ & $10 \%$ & $15 \%$ & $20 \%$ \\
\hline $\mathrm{D}$ & \multicolumn{2}{|c|}{ Sand ratio } & $33 \%$ & $35 \%$ & $37 \%$ & $39 \%$ \\
\hline $\mathrm{E}$ & \multicolumn{2}{|c|}{ Aggregate gradation } & $30 \%: 70 \%$ & $40 \%$ : $60 \%$ & $50 \%: 50 \%$ & $60 \%: 40 \%$ \\
\hline \multicolumn{7}{|c|}{ Table 2. The table of orthogonal design } \\
\hline & Number & $\mathrm{A}$ & $\mathrm{B}$ & $\mathrm{C}$ & $\mathrm{D}$ & $\mathrm{E}$ \\
\hline & 1 & $\mathrm{~A}_{1}$ & $\overline{\mathrm{B}_{1}}$ & $\overline{C_{1}}$ & $\mathrm{D}_{1}$ & $\overline{E_{1}}$ \\
\hline & 2 & $\mathrm{~A}_{1}$ & $\mathrm{~B}_{2}$ & $\mathrm{C}_{2}$ & $\mathrm{D}_{2}$ & $\mathrm{E}_{2}$ \\
\hline & 3 & $\mathrm{~A}_{1}$ & $\mathrm{~B}_{3}$ & $\mathrm{C}_{3}$ & $\mathrm{D}_{3}$ & $\mathrm{E}_{3}$ \\
\hline & 4 & $\mathrm{~A}_{1}$ & $\mathrm{~B}_{4}$ & $\mathrm{C}_{4}$ & $\mathrm{D}_{4}$ & $\mathrm{E}_{4}$ \\
\hline & 5 & $\mathrm{~A}_{2}$ & $\mathrm{~B}_{1}$ & $\mathrm{C}_{2}$ & $\mathrm{D}_{3}$ & $\mathrm{E}_{4}$ \\
\hline & 6 & $\mathrm{~A}_{2}$ & $\mathrm{~B}_{2}$ & $\mathrm{C}_{1}$ & $\mathrm{D}_{4}$ & $\mathrm{E}_{3}$ \\
\hline & 7 & $\mathrm{~A}_{2}$ & $\mathrm{~B}_{3}$ & $\mathrm{C}_{4}$ & $\mathrm{D}_{1}$ & $\mathrm{E}_{2}$ \\
\hline & 8 & $\mathrm{~A}_{2}$ & $\mathrm{~B}_{4}$ & $\mathrm{C}_{3}$ & $\mathrm{D}_{2}$ & $\mathrm{E}_{1}$ \\
\hline & 9 & $\mathrm{~A}_{3}$ & $\mathrm{~B}_{1}$ & $\mathrm{C}_{3}$ & $\mathrm{D}_{4}$ & $\mathrm{E}_{2}$ \\
\hline & 10 & $\mathrm{~A}_{3}$ & $\mathrm{~B}_{2}$ & $\mathrm{C}_{1}$ & $\mathrm{D}_{3}$ & $\mathrm{E}_{1}$ \\
\hline & 11 & $\mathrm{~A}_{3}$ & $\mathrm{~B}_{3}$ & $\mathrm{C}_{4}$ & $\mathrm{D}_{2}$ & $\mathrm{E}_{4}$ \\
\hline & 12 & $\mathrm{~A}_{3}$ & $\mathrm{~B}_{4}$ & $\mathrm{C}_{2}$ & $\mathrm{D}_{1}$ & $\mathrm{E}_{3}$ \\
\hline & 13 & $\mathrm{~A}_{4}$ & $\mathrm{~B}_{1}$ & $\mathrm{C}_{4}$ & $\mathrm{D}_{2}$ & $\mathrm{E}_{3}$ \\
\hline & 14 & $\mathrm{~A}_{4}$ & $\mathrm{~B}_{2}$ & $\mathrm{C}_{3}$ & $\mathrm{D}_{1}$ & $\mathrm{E}_{4}$ \\
\hline & 15 & $\mathrm{~A}_{4}$ & $\mathrm{~B}_{3}$ & $\mathrm{C}_{2}$ & $\mathrm{D}_{4}$ & $\mathrm{E}_{1}$ \\
\hline & 16 & $\mathrm{~A}_{4}$ & $\mathrm{~B}_{4}$ & $\mathrm{C}_{1}$ & $\mathrm{D}_{3}$ & $\mathrm{E}_{2}$ \\
\hline
\end{tabular}

According to "Durability design and construction guidelines of concrete structures" (CCES 01, 2004), the size of each test piece was $600 \mathrm{~mm} \times 600 \mathrm{~mm} \times 63 \mathrm{~mm}$, around the mold made of $10 / 6.3$ unequal angle and fixed the base plate with bolts to improve the rigidity of the mould. Each side of the mould was fixed a total of 14 and two rows of $\phi 10 \times 100 \mathrm{~mm}$ bolts to anchorage inside. Two rows of bolts were staggered to ensure the concrete filled compact[10]. The test mold was showed in Fig. 1 and two test pieces were made in one concrete mix ratio. 

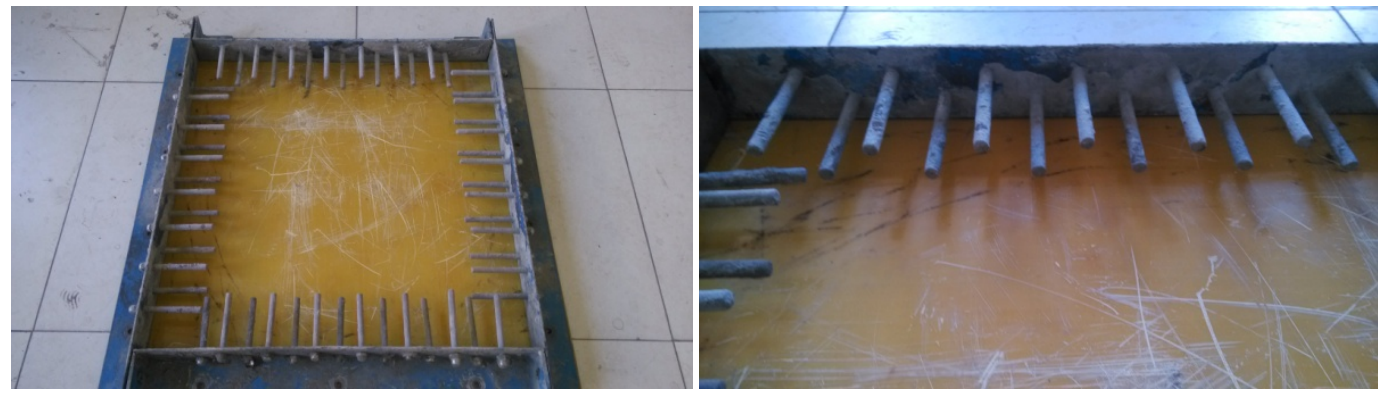

Fig. 1. The test mould of plastic shrinkage of concrete

\section{Results and Analysis}

\section{The influences of fly-ash and slag on the workability of concrete mixture}

The concrete slump was tested by experiment, and the results were shown in Fig. 2 and Fig. 3.

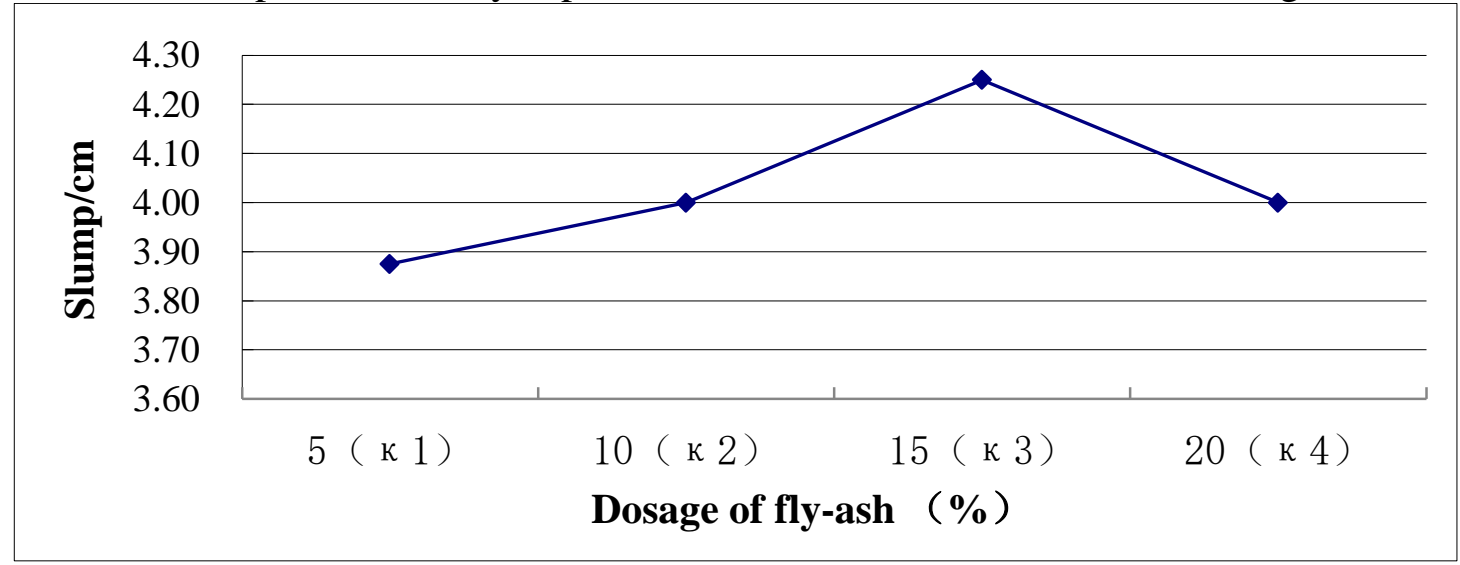

Fig. 2. The influences of different contents of fly-ash on the workability of concrete

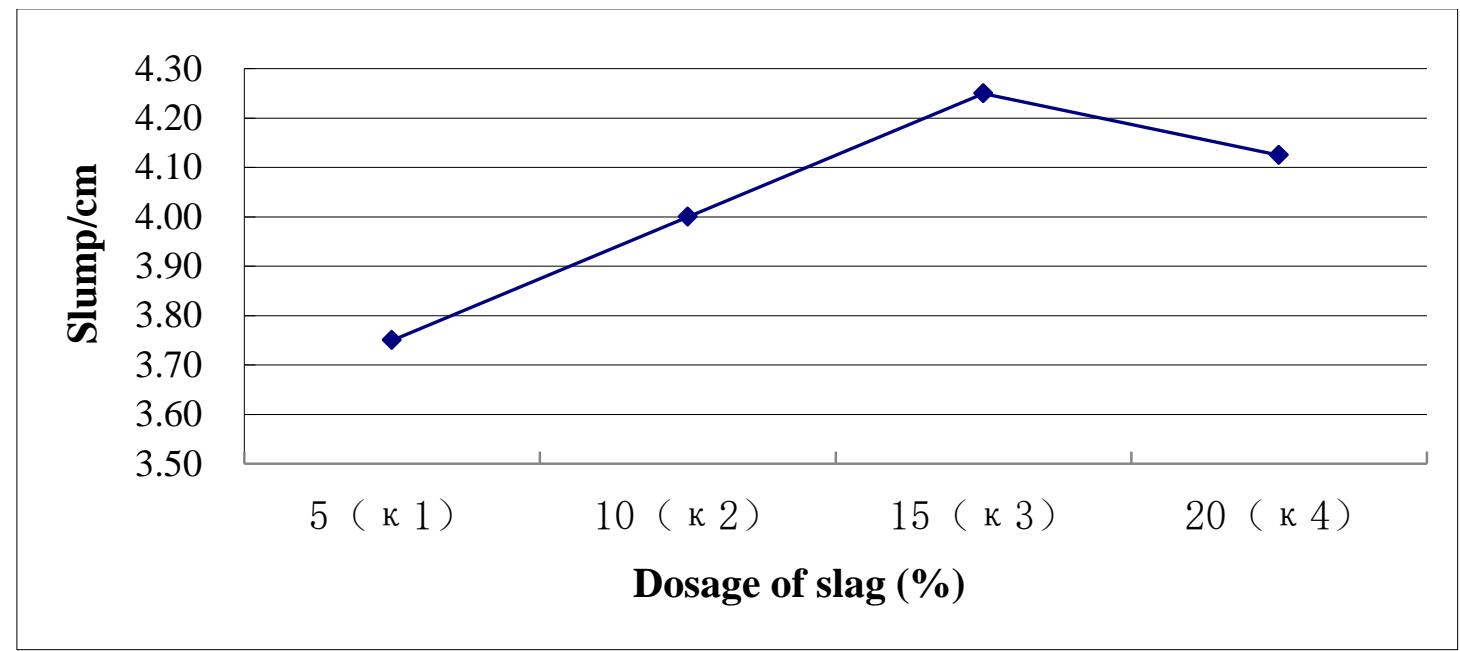

Fig. 3. The influences of different contents of slag on the workability of concrete

Fig. 2 and Fig. 3 show that with the change of contents of fly-ash and slag, the slumps of concrete mixture change accordingly. With the increase of fly-ash and slag, the slump of concrete mixture also increase, which because the particle size of fly-ash and slag is less than cement particle. After mixed in concrete mixture, fly-ash and slag can fill the gap of concrete mixture, have an effect of lubrication and improve the plasticity and cohesiveness of mixture[11]. But when the content is more than $15 \%$, the slump began to decrease. This is because when the content of flyash and slag is excessive, the dosage of cement will be reduced. After filling the gap, there will have excess of fly-ash and slag remaining and reduce the workability of concrete mixture. Because the water demand of fly-ash and slag is bigger than cement. 


\section{The influences of fly-ash and slag on the plastic shrinkage of concrete}

Concrete samples should be covered with plastic films immediately after pouring concrete, and keeping the environment temperature $30 \pm 1{ }^{\circ} \mathrm{C}$ and the relative humidity $50 \pm 5 \%$. Two hours later, removing the plastic film, then using a fan to blow the concrete surface with the wind speed of $8 \mathrm{~m} / \mathrm{s}$ and recording the cracking times, the lengths, widths and number of cracks by using a crack observation device and a ruler. In the first 3 hours, observing once every 5 minutes; once a crack was found, observing once every 5 minutes; when the piercing cracks appeared on the surface of the concrete, observing every 30 minutes a time; 1 day later, observing every 0.5 days until the age of 3 days[10]. In the first two mix, 1day later, the concrete surfaces rarely had new cracks appearing, even if appearing, the lengths and widths were tiny. Therefore, only the $24 \mathrm{~h}$ cracking was recorded in the experiment. The test data were processed and plotted to make the line charts as Fig. 4 and Fig. 5.

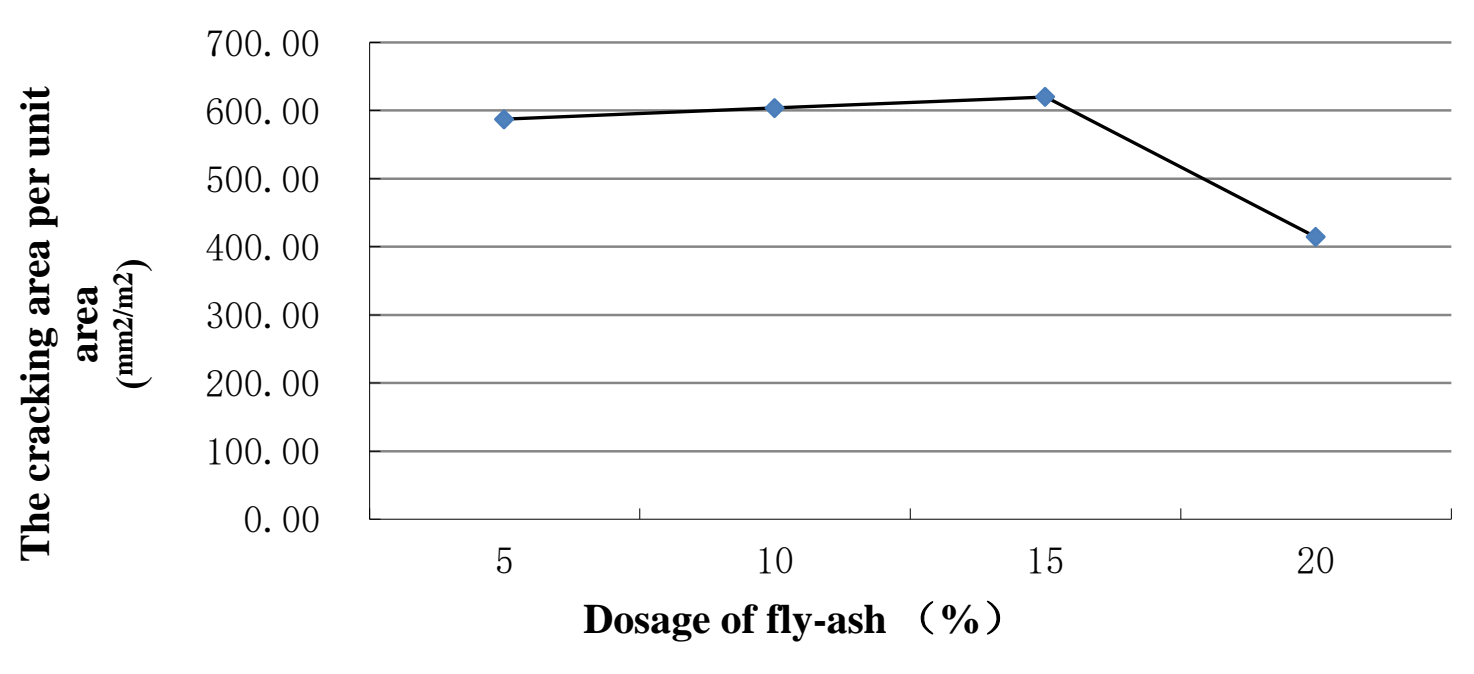

Fig. 4. The influences of different contents of fly-ash on the plastic shrinkage of concrete

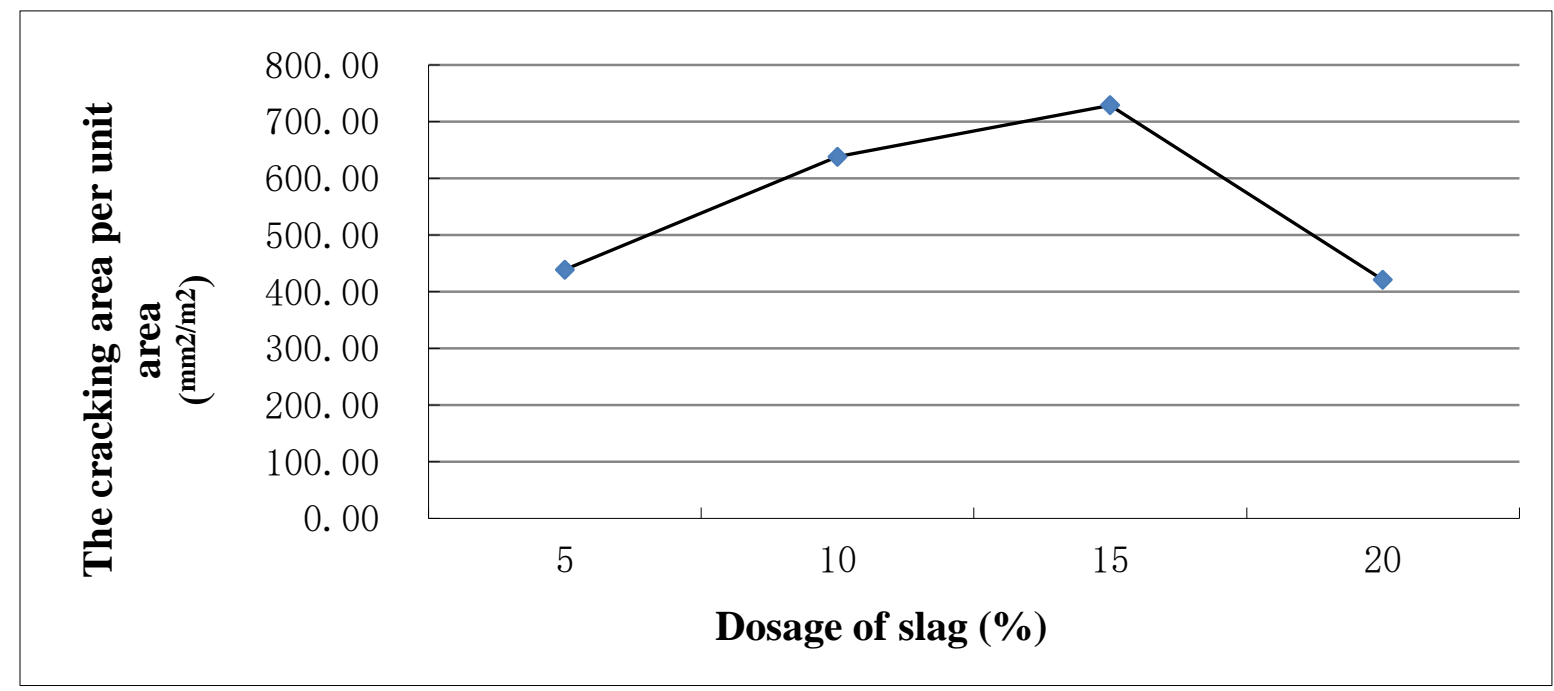

Fig. 5. The influences of different contents of slag on the plastic shrinkage of concrete

Fig. 4 shows that with the increase of contents of fly-ash, the cracking area per unit area increases first and decreases afterwards. The particle size of fly-ash is less than cement particle, after mixed in concrete mixture, fly-ash can fill the gap of concrete mixture; reduce the porosity and increase the density of the mixture. Thus slow down the rate of upward movement of water inside the concrete; increase the negative pore water pressure and improve the cracking area per unit area. But when the content of fly-ash is excessive, the dosage of cement will be reduced. Then the hydration degree of cement and the autogenous shrinkage of concrete is reduced. At the same 
time, the extra fly-ash can increase the free water content in concrete and improve the rate of upward movement of water inside the concrete. So the area of plastic cracking is smallest with the addition of $20 \%$ fly-ash.

Fig. 5 shows that with the increase of contents of slag, the cracking area per unit area increases first and decreases afterwards and the area of plastic cracking is largest with the addition of $15 \%$ slag. As same as fly-ash, slag can fill the gap of concrete mixture; reduce the porosity; increase the density of the mixture; slow down the rate of upward movement of water inside the concrete. Therefore result in the crack of the concrete surface area is increased. But the activity of slag is inferior to cement and mainly used to fill the gap of concrete mixture in the early. When slag content is over $15 \%$, the per unit volume of cement, the hydration and shrinkage of cement in the early age are reduced relatively, while the free water increases. Thus the crack area per unit area is reduced instead of the early cracking continuing to increase.

Summarize, when the quantity of the fly-ash and slag is filled to $15 \%$, although the concrete has a better workability, its porosity is low and the water in it can't be fully upward migration. So the plastic cracking area is too big. Then with the rise of the fly-ash and slag content, the workability of the concrete will decline, but the magnitude of the decline is not large, and the plastic cracking area can also be better control. So for the capacity for resisting plastic shrinkage of concrete, it is suggested that the-fly ash and slag content in concrete is suitable for $15 \%$ 20\%.

\section{Conclusions}

(1) If partial cement is replaced by fly-ash and slag, the workability of concrete can be improved. In a certain range, with the increase of fly-ash and slag, the workability of concrete is improved. Only considering the working performance of concrete, the best mixing amount of fly-ash and slag is $15 \%$.

(2) With the increase of contents of fly-ash, the cracking area per unit area increases first and decreases afterwards. When fly-ash content is more than $15 \%$, there is a significant reduction in cracking area cracking and the area is smallest with the addition of $20 \%$ fly-ash.

(3) With the increase of contents of slag, the cracking area per unit area increases first and decreases afterwards. When the slag content is $20 \%$, the crack area per unit area is the smallest.

(4) In order to guarantee the capability of resisting plastic shrinkage of concrete, considering the workability, the best content of fly-ash and slag is 15\% 20\%.

\section{References}

[1] Swayze, M.A. ,Early Concrete Volume Change and Their Control, J.ACI ,Proceedings, V.38,1942,PP425-440.

[2] Almusallam A A. Effect of Environmental Conditions on The Properties of Fresh and Harden Concrete [ J ]. Cement \& Concrete Composites, 2001, 23 : 353- 361.

[3] Yao Mingfu, The Influence of Curing on The Plastic Shrinkage of High Performance Concrete [J]. Journal of HeFei University of Technology (NATURAL SCIENCE EDITION), 2005 (2):180184.

[4] National Standards of P. R. Common Portland Cement (GB 175-2007)[S]. Beijing: National Cement Standardization Technical Committee（SAC/TC 184）, 2007.

[5] National Standards of P. R. Fly Ash Used For Cement And Concrete(GB/T 1596 2005)[S]. Beijing: National cement Standardization Technical Committee(SAC/TC 184), 2005.

[6] National Standards of P. R. Ground Granulated Blast Furnace Slag Used For Cement And Concrete (GB/T 18046 - 2008) [S]. Beijing: National Cement Standardization Technical Committee (SAC/TC 184), 2008. 
[7] National Standards of P. R. Sand For Construction (GB/T 14684-2011)[S]. Beijing: National Cement Standardization Technical Committee (SAC/TC 184) , 2011.

[8] National Standard of the people's Republic of China, the construction of gravel and gravel (GB/T 2011 - 14685) [S]. Beijing: the National Standardization Technical Committee of cement (SAC/TC 184), 2011.

[9] National Standards of P. R. Concrete Admixtures (GB 8076-1997)[S]. 1997.

[10] Standards of China Civil Engineering Society. Durability Design and Construction Guidelines of Concrete Structures (CCES 01, 2004) [S]. Beijing: China Construction Industry Press, 2005.

[11] Xi Zhizhen. High-performance Concrete of fly ash [J]. Concrete.1999, (4): 17 19. 